\title{
Customizable Volumetric High Performance Brise-Soleil System Based on the Use of Planar Faces
}

\author{
Rodrigo Velasco \\ Universidad Piloto de Colombia, Frontis3d, Colombia \\ rodrigo-velasco@unipiloto.edu.co \\ Julián Viasus \\ Frontis3d, Colombia \\ julian@frontis3d.com
}

Fabián Tocancipá

Universidad Piloto de Colombia, Colombia

fatocancipa@hotmail.com

\begin{abstract}
This paper presents a proposal for a cellular brise-soleil system appropriate for tropical humid climates. The system controls thermal gains whilst allowing for specific lighting requirements, permitting, in many cases, interior thermal and light comfort conditions without the use of thermal machines or artificial lighting. The development of the system involved a definition of variable design parameters and areas of performance evaluation and optimization, plus construction detailing development represented by a first project to be completed in 2014. Even if the geometrical definitions, optimization processes and production machinery are relatively simple and not particularly new to anyone in the field, it is claimed that the use of such already widely available technologies at this basic level, when solving relevant problems, has still to be used in generalised ways by common designers, and with the example shown, this paper wishes to promote such prospect.
\end{abstract}

Keywords: Solar shadings; Environmental simulations; Parametric models; Performance in architecture.

\section{Introduction}

Or why Brise-soleil systems

Even though the subjects of façade design and CAD/CAM fabrication have been profusely studied during the last decade or so, the relationship between those two subjects seems to have been mainly considered taking image and shape-related aspects as the main parameters without deep attention to their particular environmental performance consequences. In more general terms, some studies have proposed façade's categorizations based on their physical configuration in relation to performance (Hausladen 2008 pp. 94-118, Knaack 2007 pp. 14-34), but of those, the great majority are specific to double layer glass arrangements particular to high latitude locations. A brief look at weather data for tropical regions, however, would show that in many cases solar control and ventilation could by themselves be enough to generate interior comfort conditions, meaning that there, brisesoleil systems are of paramount importance regarding the façade environmental performance. Even when altitude implies somewhat colder temperatures, solar gains could be excessive (due to minor atmospheric protection) during some times of the day, and in the case of highly glazed buildings, could result in extremely high internal temperatures due to the greenhouse effect. The graphics below take Bogotá as an example, showing constant values of some $400 \mathrm{KWm} 2$ at midday during most of the year, which would entail interior temperatures of up to $58 \mathrm{C}$ for an unprotected glass construction located there.

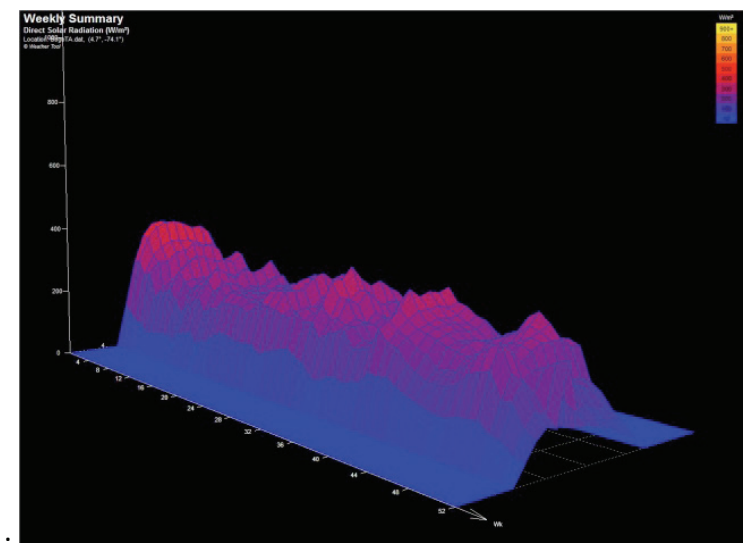

Figure 1: Bogotá, weekly radiation

The latter is the case of our concern, that is, where the project presented here is being built, even if the system may have greater advantages in warmer (lower altitude) tropical regions. Taking that into account, this paper goes beyond describing the actual built project, which should instead be understood as an instance of a broader system including design variables and performance measurement methods. It shall also be said that the work presented here has been informed by the results of the research project "Eco- envolventes" in which the main author was involved during two years (Velasco, 2011) at Universidad Piloto de Colombia. 


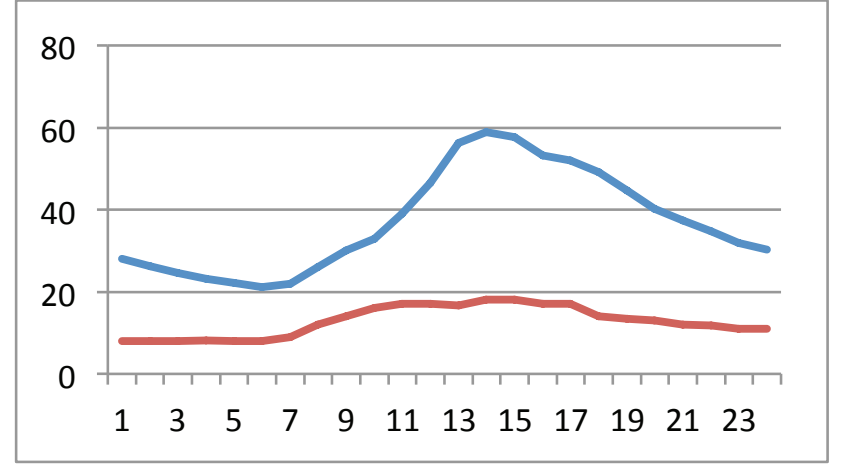

Figure 2: Bogotá interior and exterior day temperatures for a completely unprotected glass box on an average day (Data for a $3 \mathrm{~m}$ sided box, obtained using EnergyPlus via Diva for Rhino)

\section{Parametric System}

Or which design variables have been considered

In order to define the variable parameters for the cellular brisesoleil system, three main categories were identified, the first had to do with generating the $2 d(U V)$ grid, the second with the local volumetric variables regarding each $3 d$ cell in the grid, and the third with the surface material of the planar components. These parameters are shown in Fig. 3 and explained below:

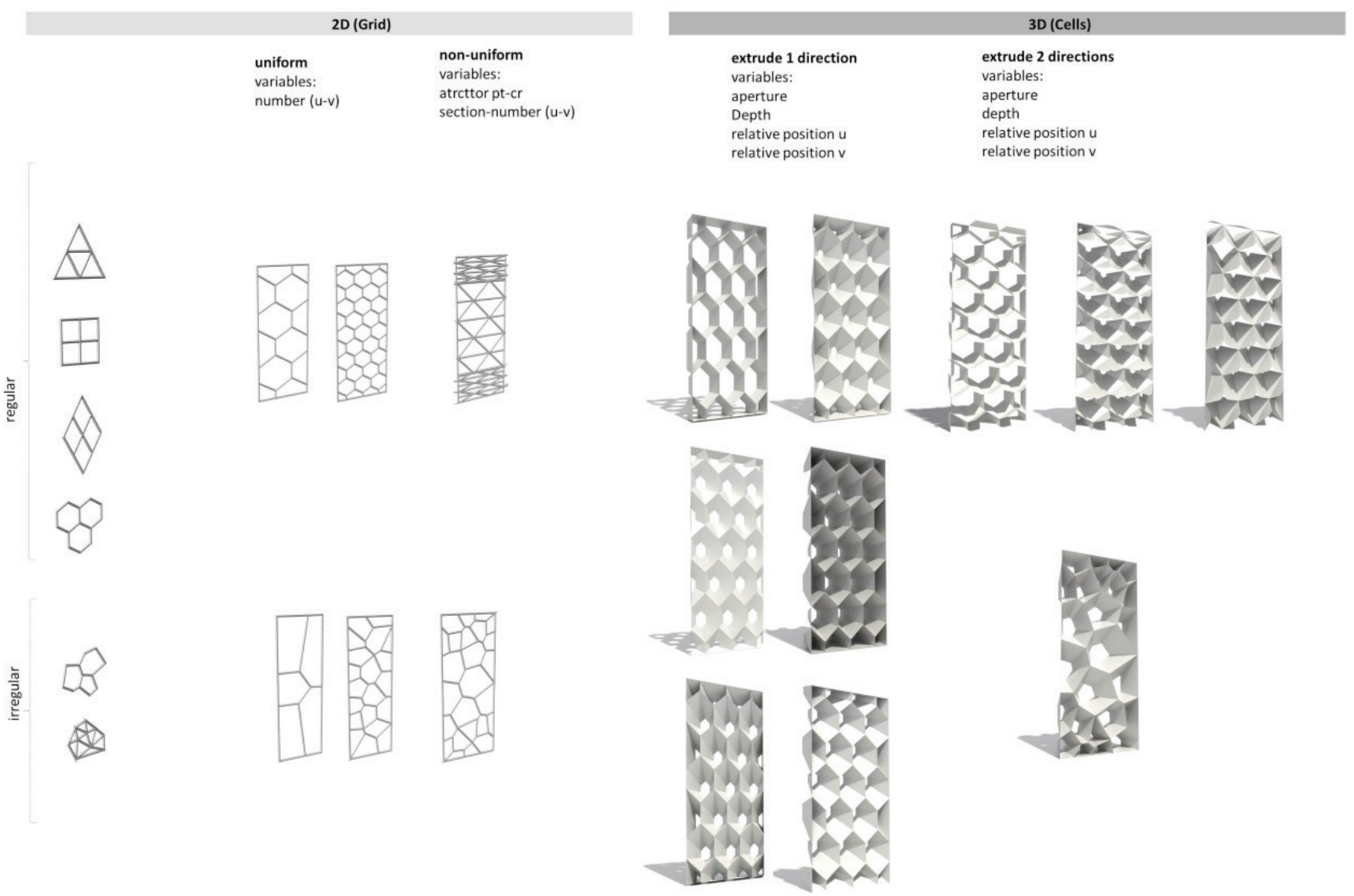

Figure 3: General system variables

\section{D - Grid parameters}

Three variables define the construction of the 2D grid from which the bise-soleil system is created:

Morphology: Defines the 2D shape of the cells in the grid. It would be possible to include an innumerable amount of possible tessellations including mixed types, but to start studying the problem only basic Triangular, Square, Rhombic and Hexagonal grids were selected as options.
Frequency: Indicates the number of cells in $\mathrm{U}$ and $\mathrm{V}$ directions of the selected surface

Regularity-Uniformity: This indicates the way in which the above parameters are applied to a particular surface, that is, the differentiation in terms of morphology and Frequency on it. Again, this would open many possibilities, but at this stage only already given irregular grids (Voronoi-Delaunay), point populations 
to define them and deformation given by point attractors are being used.

\section{D - Cell parameters}

The following 4 variables define the possible operations within a given cell in the 2D grid previously defined.

Aperture: Considering a loft between the external perimeter of a given grid cell and an offset of itself, the variable aperture indicates the offset distance, where 0 represents the original curve and 1 a hypothetical curve of length cero inscribed at the cell's centroid.

Depth: Considering again the 2 curves, depth represents the distance at which they are separated in the perpendicular direction of the offset, that is in the direction normal to the surface.

Relative Position $U$ and $V$ : This indicates the off-centring of the second curve in relation to the normal center in $U$ and $V$ directions, which for a vertical façade would mean it's horizontal and vertical relative positioning.

Extrusion Direction (Single-Double): This indicates the lofting direction for the curves in the cell, implying a single direction for closed cells and double for special configurations, here Rhombic and Hexagonal ones.

\section{Material parameters}

As an extra parameter to give control to the desired lighting effects of the system, two variables have been added to qualify the actual surface of the cells:

Perforations: A variable degree of perforations on the upper cells, i.e. those receiving only indirect light, can be controlled

Colour: This gives higher or lower reflectivity to particular surfaces according to the requirements

\section{Evaluation and Optimization Strategies}

Or how to measure and enhance the performance of the system

It is not an easy task to optimize a system, for any optimization has a limited range of aspects to be optimized, and they may in many cases oppose each other. Since the key to the problem lies in the necessary specificity of any kind of optimization, it is then of primary importance to completely understand the scope of the phrase or concept directly following the proposition for after the word optimization, that is, in our case, such system is optimized for (appropriate lighting levels, energy consumption, primary energy, global warming potential, views, etc.) performance when in use, and following from that, understanding not only the particularities of the problem (what does appropriate lighting levels, means etc.) but also, and probably most importantly, realizing for which other aspects the same design is not optimized; only an exhaustive and unbiased

Evaluation of that situation would give the designers a balance of the real value and limitations of the data produced.

Following that, this paper does not attempt at reaching a standard process for optimizing the system, but instead proposes a series of aspects that can be evaluated for different instances, and which can only have any sense when transposed to both, the particular conditions of a site and its relative positioning (e.g. Bogotá, south facing) and the requirement of the covered space (e.g. An office space with 500 to 1000 lux evenly distributed).

The graphics below show the different grid possibilities of the system analyzed for a south facing façade in Bogotá, with a frequency given by fabrication constrains (using metal sheet of 4 by 8 feet), a depth of $250 \mathrm{~mm}$ given by the building conditions, and a variable relative positioning in $\mathrm{X}$ and $\mathrm{Z}$ where local minimums for annual direct solar incidence and Cooling energy consumption were found using Galapagos from GH based on solar and thermal analyses from EnergyPlus via Diva for Rhino.

\section{Built Project and Detailing}

Or what is being built and how is it going to be assembled

The project asked for the design and construction of a facade cover that would allow the maximum levels of indirect lighting to an office space inside, whilst protecting it from direct sun rays and providing a particular image to the clients. As shown above, the solution implied a study of solar radiation angles during the year and lighting and considered sources from other openings to accommodate the system's geometry accordingly. In doing so, it was necessary to add variable degrees of perforation on particular elements to comply with the lighting requirements. Even if the Voronoi solution was not the best option in terms of material used against performance, it was chosen by the client as it gave the idea of an organic continuum.

Nonetheless, due to assembly time requirements and development times, it was decided to use a module of 8 cells that was repeated 12 times in the façade, still giving an idea of a complex, non regular design. The module was developed in two stages, the first one implied a frame structure to which planar folded sheets where welded, but it was found that the frame posed important problems to get the angles rightly welded. The second got rid of the frame by providing extra folding at the edges of each cell that would act as embedded beams, put together by CNC cut plates specific to each joint, and from which structural links could be placed to the supporting elements of the building. The geometry was adapted so those joints would coincide with levels of the existing slabs. 

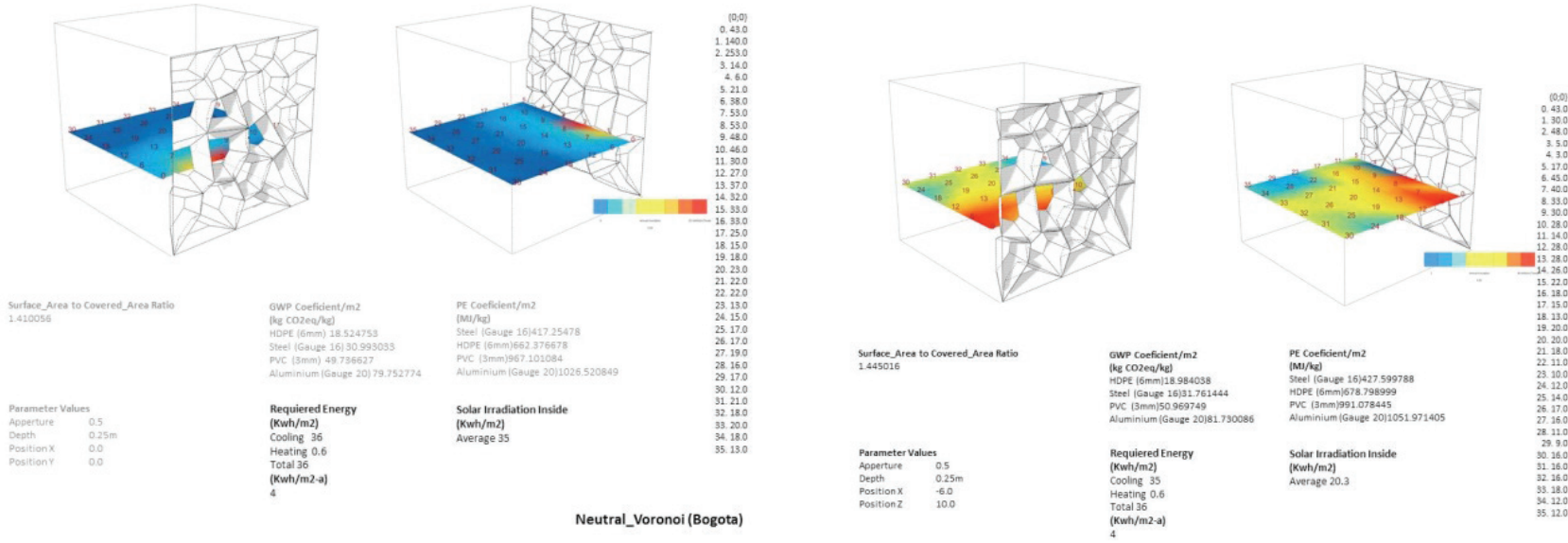

Optimized_Pos. Voronoi (Bogotol

Figure 4: Local minimums of direct lighting inside for a south facing Voronoi grid in Bogotá (Data for a 3m sided box, obtained using EnergyPlus via Diva for Rhino).

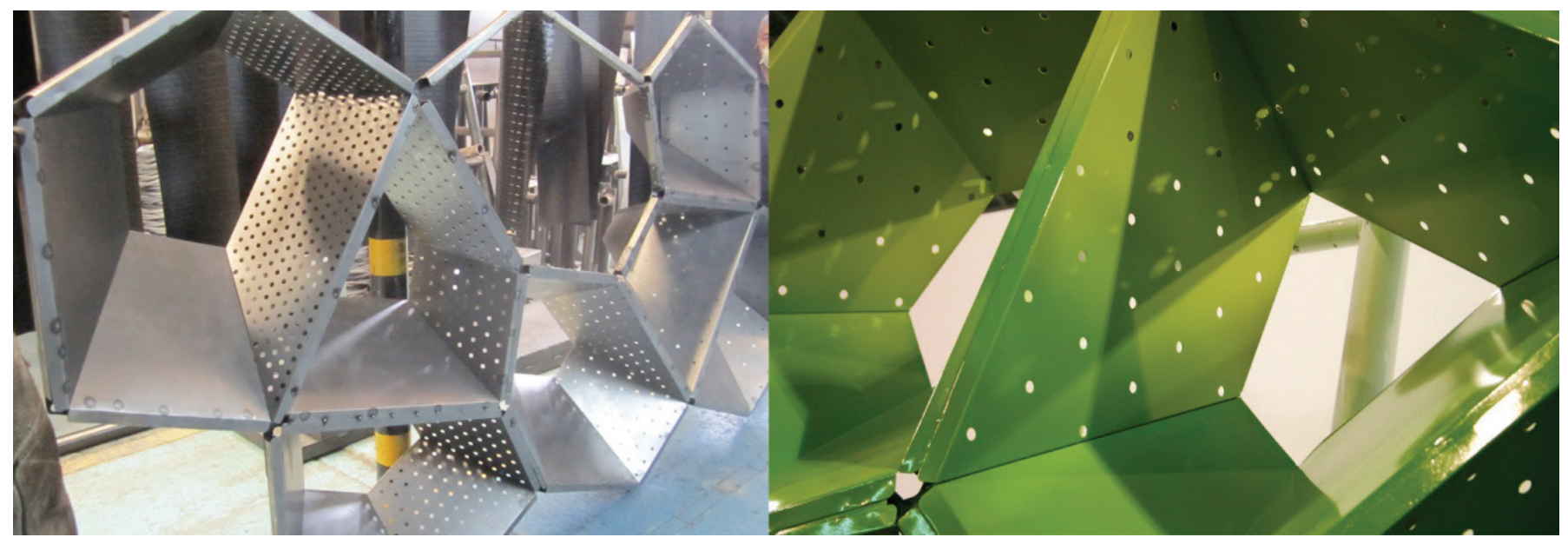

Fig. 5 First version of Voronoi cell system with frame, drawings and prototype
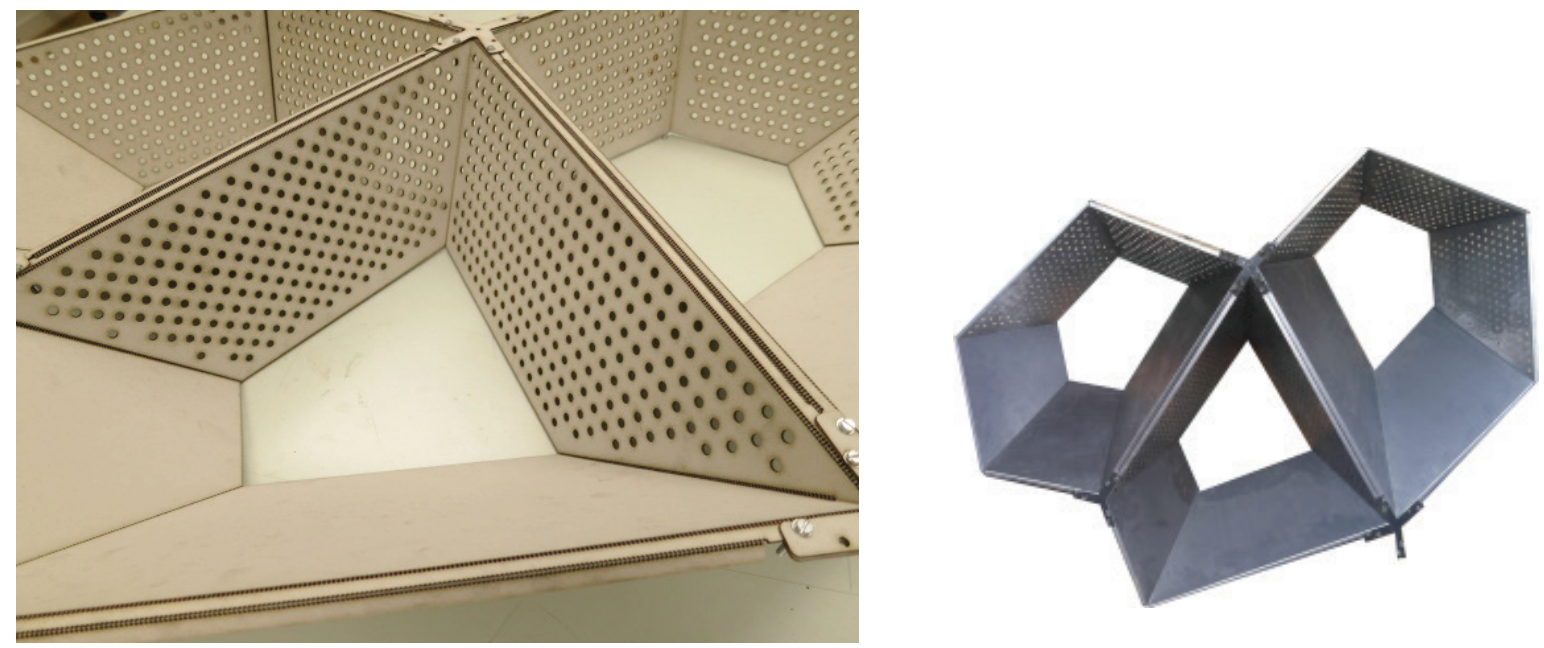

Figuere 6: Second version of Voronoi cell system (frameless), cardboard models and sprorotypes 


\section{Conclusions}

Or what has been learnt

As simple as the geometry and the processes involved in this project may be, this is an example of an application of $\mathrm{CNC}$ fabrication techniques linked to simulation tools to produce a high performance customised solution for a brise-soleil, which if understood as a parametric system, may have important potential as a generalised solution for this type of requirements, as opposed to single solutions developed entirely for a particular project.

Beyond that, however, it could be said that in order to have greater degrees of control over the performance of brise-soleil systems, besides physical configuration and manufacturing constrains, there should be additional parameters such as active movement, which even if already present in projects of the kind, are not common in typical commercial systems.

\section{Acknowledgments}

This project has been developed by a team of designers from Frontis3D and SEM Ingeniería, including, Óscar Benavides (Production) and Mauricio Osorio (3d Solid Modelling) and Orlando Ariza (Renderings)

\section{References}

Hausladen, G. (2008). Climate Skin: Building-skin Concepts that Can Do More with Less Energy, Birkhäuser, Munich.

Herzog, T. et al, Facade Construction Manual, Birkhäuser, 2004

Knaack, U., et al. (2007). Facades: Principles of Construction. Basel: Birkhäuser

Velasco, R. and Robles, D. (2011) Eco-envolventes: A parametric design approach to generate Report: 